\title{
Reformas do Estado e políticas públicas: trajetórias de democratização e privatização em educação. Brasil e Portugal, um diálogo entre pesquisas
}

\author{
Fátima Antunes ${ }^{i}$
}

Universidade do Minho, Portugal

Vera Peronii

Universidade Federal do Rio Grande do Sul, Brasil

\section{Resumo}

A partir de trajetórias concretas de investigações empíricas, o artigo debate como o Estado se relaciona com o setor privado em educação e quais as implicações para a democratização e o direito à educação, no Brasil e em Portugal. Analisa-se os modos e os sentidos em que o Estado assume novos papéis, em alguns casos financiando, enquanto em outros o financiamento é privado, em alguns casos permanecendo o poder público no controlo e em outros assumindo o privado a direção e o controlo das políticas. Nesse sentido, à crescente centralidade da educação nas políticas públicas parece corresponder, entre outros fenómenos, uma ampliação das respostas e das populações abrangidas acompanhada da multiplicação das modalidades de privatização e de mercadorização da educação. Conclui-se que a lógica mercantil tem participado ativamente na direção e execução das políticas educacionais, com graves consequências para o processo de democratização.

Palavras-chave

Redefinições no papel do Estado; Políticas educacionais; Gerencialismo; Mercadorização da educação; Direito à educação 


\section{Introdução}

Este texto propõe-se realizar um diálogo entre duas pesquisadoras que, desde realidades próprias, analisam, a partir de estudos recentes, as redefinições do papel do Estado neste período particular do capitalismo e a sua materialização nas políticas educativas, e, mais especificamente, como as fronteiras entre os domínios público e privado estão continuamente a modificar-se, ficando cada vez menos precisas, nas políticas sociais em geral, e na educação em particular.

Tanto no Brasil (no período de abertura política, pós 1985) quanto em Portugal (após a revolução de abril de 1974 e a instauração da democracia), os avanços das lutas por direitos sociais aconteceram no momento pósditadura, no mesmo período em que entrava em crise o modelo fordista/keynesiano (cf. Antunes, 1999; Santos, 1990). Em seu lugar, o capitalismo propunha um conjunto de estratégias para retomar o aumento das taxas de lucro, reduzindo direitos, com graves consequências para a construção da democracia e da efetivação dos direitos sociais.

Os dois países viveram um processo de democratização recente, enquanto por todo o mundo o mercado novamente assume um maior protagonismo, retomando princípios da sua lógica própria, como o individualismo, a competitividade, a produtividade, a avaliação com foco no produto. Isso ocorreu em detrimento da construção de valores democráticos, como a aprendizagem da participação, da coletivização das decisões e do conhecimento como um direito.

O diálogo tem esta entrada comum, apesar de as pesquisas terem caminhos específicos, explorando no Brasil diversos casos e modalidades de reconstrução do papel do Estado, tanto no avanço do direito à educação, quanto dos processos de privatização da direção e execução das políticas educacionais. Os estudos evocados sobre Portugal visibilizam novos papéis para o Estado, no quadro de processos de democratização, europeização e privatização da educação, fomentando a contratualização da provisão pela via do financiamento por programas europeus.

Procura-se, através desta interlocução entre pesquisas, examinar e sublinhar a dimensão dinâmica, relacional e processual das realidades e fenómenos socioeducacionais em estudo; pretende-se insistir que, quer do 
ponto de vista analítico (o estudo das relações sociais), quer fenomenológico (as formas observadas), a reconstrução do Estado e do seu papel no bemestar social em educação, bem como das relações entre os domínios público e privado, continuam em aberto e em mudança. Os conflitos em torno da reestruturação do capitalismo, da negociação do contrato social, da disputa sobre a redistribuição do rendimento, em curso desde os anos 70 do século passado, desenham ainda os contornos de realidades que se procura questionar.

A seguir apresentaremos as pesquisas, os seus enfoques teóricometodológicos e alguns dados que nos permitam conhecer como os processos de reforma do Estado e de privatização ocorrem suportados pelas políticas públicas de educação nos dois países. No final, retomaremos o debate em torno do que é possível compreender através das nossas pesquisas sobre materializações específicas das redefinições entre o público e o privado e do papel do Estado, com implicações na consecução do direito à educação e para o processo de democratização nas realidades nacionais em estudo.

\section{Uma diversidade de papéis e de relações do Estado e do privado em educação: 0 que as pesquisas demonstram sobre o Brasil}

A pesquisa sobre a parceria de escolas públicas com o Instituto Ayrton Senna envolveu grupos de dez estados brasileiros para analisar as suas implicações em realidades regionais tão diversas como a brasileira. A investigação atual tem por objetivo analisar como as redefinições no papel do Estado reorganizam as fronteiras entre o público e o privado, materializandose das mais diferentes formas na educação básica pública, e as suas implicações para o processo de democratização da educação no Brasil.

Entendemos que as fronteiras entre o público e o privado têm-se modificado no contexto atual de crise do capitalismo e as suas estratégias de superação - neoliberalismo, globalização, reestruturação produtiva e terceira via - redefinem o papel do Estado, principalmente para com as políticas sociais.

O neoliberalismo e a forma de social-democracia conhecida como terceira via (Giddens, 2001) têm o mesmo diagnóstico de que o culpado pela 
crise é o Estado e que o mercado deve ser parâmetro de qualidade. O papel do Estado para com as políticas sociais é alterado, pois, com esse diagnóstico, as prescrições são no sentido de racionalizar recursos e esvaziar o poder das instituições, já que se alega que as instituições públicas são permeáveis às pressões e demandas da população e improdutivas, pela lógica de mercado. Nessa perspetiva, a responsabilidade pela execução e direção das políticas sociais deve ser repassada para a sociedade. Assim sendo, tanto o neoliberalismo quanto a Terceira Via trazem implicações para o projeto democrático, por quererem esvaziar as instituições públicas das decisões. 0 neoliberalismo porque se acredita que a democracia é responsável pelas demandas sociais que provocam a distribuição de renda através das políticas públicas, ocasionando o défice fiscal. A Terceira Via, por sua vez, por ter o mesmo diagnóstico de crise do Estado; a sua proposta de reformá-lo passa por princípios gerenciais, com a lógica da sociedade civil empreendedora que deve executar as tarefas do Estado (Peroni, 2013). De alguma forma, as duas teorias propõem a transferência para a sociedade, em alguma medida, da direção e da execução das políticas sociais, o que Rhodes (1996) define como a privatização via direção e execução das políticas educativas.

Depreendemos que essa situação envolve um processo de mercantilização da educação sem precedentes na história. Rikowski (2014) ajuda-nos a entender tal processo, quando apresenta os conceitos de mercantilização, comoditização e capitalização. E cita Marginson (1997), que apresenta a 'mercantilização' como uma síntese das tendências dos mercados na educação, composta pelos processos sociais e económicos que fomentam o desenvolvimento, a intensificação e a força dos mercados na educação e outras áreas da vida social. Ainda citando Marginson (1997), Rikowski (2014, p. 28) apresenta cinco características necessárias para o estabelecimento de um mercado educacional: 1. Os mercados envolvem a produção de mercadorias (commodities) (que são compradas e vendidas); 2. Há um campo de produção definido (por exemplo, escolaridade, formação ou ensino superior); 3. Há uma troca monetária entre produtor e consumidor de mercadorias (commodities); 4. Existem relações de concorrência entre os produtores; 5. Há mercado de subjetividades - as atitudes e comportamentos adequados ao mercado de produção, consumo e troca. Verificamos que o processo de mercantilização envolve, no caso brasileiro, o campo da 
educação e a constituição desta como mercadoria, conforme as características 1 a 4 do autor (cf. Adrião \& Garcia, 2014; Adrião, 2014; Adrião, Garcia, Borghi, \& Arelaro, 2009; Robertson \& Verger, 2012). Parece ainda estar em curso a formação de subjetividades, quanto às atitudes e comportamentos vinculados ao mercado de produção, consumo e troca, para que tem sido chamada a atenção em pesquisas em torno do conteúdo da educação (cf., por exemplo, Peroni, 2015, 2016).

Laval (2004) também apresenta várias formas de mercantilização na educação: a que destina a escola a fornecer mão-de-obra adaptada às necessidades da economia; a intervenção mais direta das empresas na pedagogia, conteúdos escolares, validação das estruturas curriculares e diplomas, que pretende instituir nas escolas a lógica de mercado; a adoção de escolas por empresas, interferindo no seu programa educativo; a publicidade, através do financiamento de artigos escolares com o logo da empresa. Laval (2004) observa, ainda, que esses movimentos geram dois tipos de fenómenos: a escola como mercado (publicidade ou venda de produtos) e a escola como produtora de mercadorias específicas (suportes e conteúdos de ensino). Verificamos que, mais do que privatizar escolas, importa ao mercado interferir na política educacional, principalmente nos casos de parcerias dos Institutos Ayrton Senna e Unibanco com escolas do ensino fundamental e médio, em que o conteúdo da educação é monitorizado, com metas estabelecidas pelos Institutos, o que Laval chama de "mercadorias específicas" (Peroni, 2016).

Concordamos que o processo de mercantilização ocorre também quando o privado define o conteúdo da educação. Semelhante processo de privatização do público tem consequências para a democratização da educação, pois concordamos com Vieira (1998) quando diz que "não há estágio democrático, mas há processo democrático pelo qual a vontade da maioria ou a vontade geral vai assegurando o controle sobre os interesses da administração pública" (p. 12). Afirma também: "Quanto mais coletiva a decisão, mais democrática ela é. Qualquer conceito de democracia, e há vários deles, importa em grau crescente de coletivização de decisões" (Vieira, 1998, p. 12). No entanto, a coletivização das decisões como parte da construção do processo democrático foi cada vez mais subsumida pelo processo de privatização da educação. 
Destacamos que, nas nossas pesquisas, entendemos que a mercantilização da educação pública não é uma abstração, mas ocorre via sujeitos e processos. Trata-se de sujeitos individuais e coletivos que estão cada vez mais organizados, em redes do âmbito local ao global, com diferentes graus de influência e que falam de diferentes lugares: setor financeiro, organismos internacionais, setor governamental. Algumas instituições têm fins lucrativos e outras não, ou não claramente, mas é importante destacar que entendemos as redes como sujeitos (individuais e coletivos) em relação com projetos de classe (Peroni, 2016).

Wood (2014) também trata do importante papel do Estado para o capital neste período particular do capitalismo, de financeirização e globalização: "O capital global ainda (na verdade, mais do que nunca) exige uma ordem política, social e legal rigidamente regulada e previsível" (p. 11). A autora argumenta que

o capitalismo precisa de estabilidade e previsibilidade nas suas organizações sociais. O Estado nação ofereceu isso por meio de uma elaborada estrutura legal e institucional, apoiada pela força coercitiva, para sustentar as relações de propriedades do capitalismo, seu complexo aparelho contratual e suas intrincadas transações financeiras. (Wood, 2014, p. 26)

Alguns autores apontam que o estado nacional está em declínio; no entanto, para a autora, o "Estado é hoje mais essencial do que nunca para o capital mesmo - ou especialmente - em sua forma global. A forma política da globalização não é um estado global, mas um sistema global de Estados múltiplos" (Wood, 2014, p. 18). E a autora explica por que o Estado é tão importante para a acumulação de capital no período de financeirização do capital: "o poder económico do capital não pode existir sem o apoio da força extra-económica; e a força extra-económica é hoje, tal como antes, oferecida primariamente pelo Estado" (Wood, 2014, p. 18).

Assim, a globalização, principalmente a financeira, mas também a produtiva, com as mudanças nos mercados mundiais, não minimiza o papel do Estado, mas o redefine. Enfim, são mudanças profundas não apenas na produção, mas no modo de vida da sociedade. Entendemos que essas redefinições no papel do Estado modificam as fronteiras entre o público e o privado e materializam-se das mais variadas formas.

Entendemos que, se as redefinições no papel do Estado e o aumento da privatização em âmbito internacional (cf. Ball \& Junemann, 2012; Ball \& 
Olmedo, 2013; Ball, 2012; Robertson \& Verger, 2012; Robertson, Mundy, Verger, \& Menashy, 2012) apresentam importantes implicações para o processo de democratização e para a minimização de direitos universais e de qualidade para todos, tal é ainda mais problemático em países que viveram ditaduras e estão num processo recente de luta por direitos materializados em políticas.

Desse modo, é importante ressaltar a especificidade brasileira na análise das redefinições do papel do Estado, pois ele foi, historicamente, vinculado aos interesses privados (cf. Pires, 2015; Vieira, 1998). Os avanços das lutas por direitos sociais ocorreram no momento pós-ditadura, na década de 1980, em que entraram em debate processos de democratização da educação, participação, coletivização das decisões, assim como direitos sociais materializados em políticas. Ao mesmo tempo, os processos de neoliberalismo, reestruturação produtiva e financeirização redefiniam o papel do Estado para com as políticas sociais, com um diagnóstico de crise fiscal e redução de custos, com graves consequências para a construção da democracia e da efetivação dos direitos sociais, materializados em políticas públicas, dando lugar ao que temos chamado de "naturalização do possível" (cf. Peroni, 2003, 2013). Ocorreram avanços inegáveis no acesso à educação, como a ampliação de direitos pela universalização do acesso, inclusão de alunos com necessidades especiais, maior participação na vida escolar; no entanto, não ocorreram as condições materiais com a mesma intensidade das mudanças, que foram realizadas com os "recursos possíveis" e, muitas vezes, em detrimento de salários e condições de trabalho dos profissionais da educação.

Assim sendo, vivemos a contradição de que estamos avançando lentamente em alguns direitos materializados em parte na Constituição Federal de 1988 e na Lei de Diretrizes e Bases (LDB) de 1996, como a gestão democrática da educação, a educação básica entendida como educação infantil, fundamental e média, a gratuidade da educação pública, entre outros. $\mathrm{E}$, ao mesmo tempo, num processo de correlação de forças, a privatização do público é cada vez maior, conforme analisamos nas pesquisas apresentadas neste artigo. Não temos a pretensão de mostrar todas as formas de privatização do público, pois são muitas e cada vez mais variadas; assim, escolhemos estudar em cada etapa e modalidade da educação básica a que 
melhor a materializa. Tivemos a intenção, também, de demonstrar diferentes processos em que o setor público transfere a execução ou em que a oferta é pública mas o privado assume a direção, como nas parcerias, conforme apresentaremos nos próximos itens.

\subsection{A oferta permanece pública e o privado atua na direção e execução definindo o conteúdo da educação via parcerias}

No ensino fundamental e médio no Brasil, a garantia do acesso à educação pública foi ampliada, o que consideramos um avanço neste processo. No entanto, também verificamos a presença cada vez maior do privado mercantil na definição da educação pública. O Estado continua a ser o responsável pelo acesso, e inclusive amplia as vagas públicas, mas o "conteúdo" pedagógico e de gestão da escola é cada vez mais determinado por instituições que introduzem a lógica mercantil, com a justificação de que, ao agir assim, estão a contribuir para a qualidade da escola pública. A oferta é pública em $84,26 \%$ das matrículas no ensino fundamental (EF) e $86,75 \%$ do ensino médio (EM), sendo que em instituições privadas estão inscritos apenas $15,73 \%$ dos alunos no EF e $13,25 \%$ no $\mathrm{EM}^{1}$. A oferta aumentou para quem historicamente não teve acesso e esta ampliação ocorreu na escola pública. O que se privatizou nestas etapas do ensino obrigatório foi o que chamamos de "conteúdo da educação". A privatização ocorre através de parcerias (cf. Adrião \& Peroni, 2010) ou venda de sistemas privados (cf. Adrião et al., 2009). As parcerias envolvem processos de privatização da escola pública, através da execução e da direção, pois definem o conteúdo da educação e executam a sua proposta por meio da formação, da avaliação, da monitorização, da premiação e de aplicação de sanções que permitem um controlo de que o seu produto será executado.

Demos prioridade, nas pesquisas, às parcerias que têm atuação nacional e influenciam em maior escala a educação pública no Brasil, como foi o caso do Instituto Ayrton Senna (IAS), no ensino fundamental, e do Instituto Unibanco, no ensino médio. Os Institutos atuam no conteúdo da educação através da formação de professores, do material didático, da rotina das aulas, e também através da monitorização das escolas e da atuação do professor, numa relação de controlo e exigência dos resultados. A atuação do setor privado ocorre cada vez mais na direção das políticas, com o pressuposto de que a qualidade da educação deve ser definida pela lógica de mercado. 
O financiamento ocorre em parte através do governo federal ou da renúncia de receitas, em que as empresas deixam de pagar impostos cujo montante doam para estes Institutos. É importante ainda destacar que não há controlo público efetivo sobre onde são gastos os recursos das renúncias de receitas ${ }^{2}$.

Os Institutos sabem que não adianta ter apenas as grandes normas da política e da educação e que é preciso influenciar na sala de aula para efetivar a mudança. O Instituto Ayrton Senna (IAS) iniciou programas complementares no período inverso ao das aulas e depois apenas em classes de aceleração, mas passou a influenciar na política educacional como um todo, indo desde o currículo e a aula até à gestão do sistema e da escola. O Instituto percebeu que, para ter mudanças substantivas, não adiantaria atuar apenas em questões focalizadas, mas na educação como um todo. Portanto, atualmente planeia, monitoriza e avalia os sistemas públicos através da Rede Vencer.

O IAS vincula a aprendizagem à gestão das escolas. Entende que a escola deve ter uma gestão gerencial, rigidamente monitorizada e com atividades padronizadas, através de aulas prontas e uma rotina pré-fixada. Define que o foco deve ser na matemática e na língua materna, que são as atividades avaliadas nas provas nacionais. Entende que a aprendizagem é um produto, que pode ser mensurado através dos resultados das avaliações e de metas pré-estabelecidas (cf. Adrião \& Peroni, 2010).

O Instituto Unibanco (IU) atua em escolas de ensino médio com o Projeto Jovem de Futuro (PJF), em parceria com o Ministério da Educação, no Programa Ensino Médio Inovador (PROEMI). A parceria passou a chamarse ProEMI/JF. A proposta do PROEMI é focada no currículo, enquanto o PJF apresenta uma proposta mais vinculada à gestão da escola como indutora da aprendizagem dos alunos. Para o Instituto Unibanco, a gestão da escola é considerada ineficiente e ineficaz, e propõe a Gestão Escolar para Resultados (GEpR), que adota sistemas de informação voltados para a monitorização, controlo e avaliação. Este deslocamento do currículo para a gestão é parte do diagnóstico neoliberal, de que a crise atual é uma crise de má gestão do setor público, que com uma gestão gerencial seria resolvida. Este diagnóstico parte de um pressuposto de que a aprendizagem é um produto e que deve ser mensurada e tratada através de mecanismos gerenciais para que o 'resultado' esteja de acordo com as metas definidas (cf. Caetano \& Peroni, 2015). 
Verificamos que nos dois Institutos estudados são reforçadas as disciplinas vinculadas às avaliações internacionais, os métodos são padronizados e replicáveis, menos críticos e com cada vez menos conhecimento. E estes processos têm-se estabelecido com certa naturalidade na comunidade educacional e sociedade em geral, pois são muitas vezes vistos como sucesso escolar.

\subsection{0 poder público transfere a execução da oferta educacional para o setor privado com ou sem fins lucrativos}

Destacamos que, no ensino fundamental e médio, a oferta foi expandida via escola pública e a privatização ocorreu mais no conteúdo da educação; no entanto, outras etapas da educação básica, como a educação infantil ou as modalidades de educação de jovens e adultos (EJA) e educação profissional, vivem outro processo em que o poder público transfere a execução da oferta educacional para o setor privado com ou sem fins lucrativos, como forma de barateamento ou racionalização de recursos. Por exemplo, nas creches e na Educação de Jovens e Adultos (EJA), setores mais frágeis envolvendo crianças ou adultos que não tiveram acesso à educação, muitas vezes não são contratados professores com formação, já que os professores concursados lentamente adquiriram direitos e a transferência de responsabilidades (terceirização) é feita com profissionais mais baratos, muitas vezes voluntários, o que consideramos um processo de precarização do trabalho docente. Um estudo de Susin (2009) demonstra que nas creches comunitárias os espaços nem sempre são adequados, os processos democráticos no interior da escola, que foram uma conquista da escola pública, nas instituições contratadas não estão normalmente presentes. A admissão dos estudantes não tem critérios transparentes e nem sempre o ensino é gratuito. Normalmente são instituições para alunos muito pobres, e mesmo uma mensalidade baixa já onera o orçamento das famílias, o que consideramos questionável do ponto de vista do direito à educação, pois no Brasil muito lutamos pela gratuidade da educação pública.

$\mathrm{Na}$ EJA, observamos ainda que os professores muitas vezes são contratados em outro turno com bolsa, recebendo menos do que o seu salário, o que também entendemos como uma forma de precarização (cf. Brasil, 2012; Comerlato \& Moraes, 2013). 
$\mathrm{Na}$ educação profissional destacamos o programa proposto pelo governo federal em 2011, o PRONATEC (Programa Nacional de Acesso ao Ensino Técnico e Emprego), que visa a melhoria da qualidade do ensino médio público por meio da articulação com a educação profissional e a ampliação das "oportunidades educacionais dos trabalhadores por meio do incremento da formação e qualificação profissional" (Brasil, 2011b, art. 2). Para a execução do programa está prevista a participação de instituições privadas: "O PRONATEC poderá ainda ser executado com a participação de entidades privadas sem fins lucrativos, devidamente habilitadas, mediante a celebração de convênio, acordo, contrato, ajuste ou instrumento congênere" (Brasil, 2011b, art. 8). Questionamos a conceção de trabalho proposta pelo governo federal, que, ao transferir recursos também para instituições privadas para execução do programa, abre mão de uma proposta de formação profissional.

Verificamos também que, ao mesmo tempo, expandiu-se a rede pública de educação profissional, mas não ao ritmo necessário, e em paralelo foi feita a ampliação via parcerias, através do PRONATEC (cf. Brasil, 2011b; Rodrigues \& Santos, 2013).

A Educação Especial foi historicamente vinculada a instituições filantrópicas e vista como caridade. Quando lutamos por educação para todos, pensamos em todos com as suas especificidades. Foi definido um processo denominado de inclusão em que as crianças com necessidades especiais foram acolhidas nas escolas regulares. No entanto, tal ocorreu, com algumas exceções, sem recursos humanos e materiais para que a inclusão fosse feita com qualidade. Assim que, atualmente, ocorre o retorno de parcerias com as instituições filantrópicas (cf. Borowsky, 2013; Peroni, 2011).

Apesar de, nas normas, o poder público ter alguma regulação, na prática muitas vezes não há fiscalização, ou há o entendimento de que é melhor garantir o funcionamento precário do que fechar e deixar a população desassistida.

Verificamos que, apesar de uma das justificações para transferir responsabilidades para o setor privado ser a racionalização de recursos, o poder público, em alguns processos, diminui custos para as populações mais vulneráveis com as creches, a educação de jovens e adultos, a educação profissional, mas, por outro lado, contrata assessorias e parcerias e compra 
produtos privados que oneram em muito o orçamento (cf. Bittencourt \& Oliveira, 2013).

\subsection{A atuação do setor privado na direção das políticas educativas}

Apesar de serem muitos os editais, formas de terceirização e compra dos mais diversos "produtos", desde a formação, gestão, aprendizagem, apresentamos aqui a influência dos empresários na direção das políticas educativas e venda de produtos educacionais através do Movimento Todos pela Educação (TPE). O Movimento TPE atua influenciando a agenda da política educacional no país, monitorizando e avaliando resultados e pressionando diretamente o poder executivo e legislativo para cumprir o seu programa educacional.

Destacamos a presença de empresários vinculados ao Movimento TPE na venda de tecnologias educacionais, através de um Guia de Tecnologias certificado pelo governo federal. O Guia é parte do Plano de Desenvolvimento da Educação $(P D E)^{3}$, que prevê ações de assistência técnica e/ou financeira, que podem ser solicitadas pelos municípios em quatro dimensões: gestão educacional; formação de professores e de profissionais de serviço e apoio escolar; práticas pedagógicas e avaliação; infraestrutura física e recursos pedagógicos (cf. Bernardi, Uczak, \& Rossi, 2015; Brasil, 2011a).

Quanto à atuação do Estado neste processo de relação públicoprivado verificamos que, em muitos casos, o Estado continua a financiar os programas, apesar de a execução ser privada. No que se refere à direção, observamos em alguns casos que o poder público continua a ser o executor, mas a direção e o controlo passam para instituições privadas, como nos casos brasileiros do Instituto Ayrton Senna e Instituto Unibanco.

Quanto ao controlo, observamos que o Estado em parte permanece atuando, no Brasil, por via da avaliação institucional, mas também através dos editais de contratação das instituições do terceiro setor, que vão executar as políticas educativas. Neste caso, o governo acaba por definir um determinado 'produto' e contrata quem se ajusta a este perfil. Isto também prejudica o processo de democratização, já que o desenvolvimento das políticas educativas não ocorre no âmbito de instituições públicas, permeáveis à correlação de forças, num processo de coletivização das decisões. 
Este é outro ponto polémico da relação entre o público e o democrático. Quando o governo compra um 'produto' educacional através de editais com recursos vultuosos, ocorre o contrário da democratização como coletivização das decisões, que tratamos no início do artigo, e fortalece-se a ideia neoliberal de retirar o poder das instituições públicas por serem permeáveis à correlação de forças (cf. Buchanan, MacCormick, Tollison, \& Pardo, 1984). As instituições públicas, se são democráticas, são o espaço da correlação de forças, e o produto final, num processo verdadeiramente democrático, não pode ser definido a priori. É importante resgatar as instituições públicas como espaços democráticos, com interesses coletivos e com parâmetros de justiça social.

\section{Portugal. Uma problemática para um questionamento sobre a construção do Estado de Bem-estar: Globalização, europeização, governação e gerencialismo}

Os estudos aqui discutidos sobre educação em Portugal partem de um enfoque teórico-metodológico que partilha as principais perspetivas analíticas desenvolvidas pelo grupo de pesquisas brasileiro; as questões de investigação que, de seguida, são especificamente exploradas procuram articular as problemáticas da governação e da reforma do Estado gerencial, no quadro da globalização e europeização da educação. Estes questionamentos pretendem contribuir para elucidar transformações do papel do Estado, que envolvem processos de privatização, no domínio do bem-estar e dos direitos sociais, em particular o direito fundamental à educação, no nosso país, a partir dos anos 80 do século passado.

A problemática da governação e da reforma do Estado gerencial é convocada para dar conta da criação de novas modalidades de provisão da educação (e outros bens e serviços que concretizam direitos sociais) e de coordenação sociopolítica que envolvem a reconstrução em novos moldes da centralidade (para fazer o quê? Em nome e em benefício dos interesses de quem?) e das prioridades do Estado e outras autoridades políticas (a União Europeia (UE), por exemplo) (cf. Clarke \& Newman, 1997; Dale, 1997). Tem vindo assim a ser progressivamente fabricado um universo educacional de fronteiras movediças, "formas organizacionais hibridizadas, arranjos de governança inovadores" (Newman \& Clarke, 2012, p. 353), com "o 
envolvimento de uma multiplicidade de novos provedores de diferentes tipos, e a redistribuição de poder e responsabilidade" (Junemann \& Ball, 2013, p. 423). Os fenómenos de desestatização do regime político ocorrem então a par e passo com desenvolvimentos de desnacionalização do Estado, alterando escalas, atribuições, protagonistas (Jessop, 1995, cit. em Santos, 2001), e impulsionando, no dizer de alguns, uma deslocação de governo para governação (a shift from government to governance) (Jessop, 1995). Lançado no bojo das crises do capitalismo e da democracia e na sequência das críticas e propostas, de sinal contrário, em torno da legitimidade ou da governabilidade, o programa da governação, entendida como matriz de regulação sociopolítica de orientação hegemónica, é tematizado a partir daquela última (Santos, 2005). É esse o sentido das tendências e propostas de mudança de regime, em torno da privatização, mercantilização e liberalização, dominante entre meados dos anos 80 e 90. Por seu lado, também as reivindicações de participação popular, inclusão e justiça sociais marcam a agenda política da governação contra-hegemónica, promovida por atores e processos comprometidos com a interpelação do capitalismo e da democracia em termos de redistribuição e emancipação social e protagonizada por uma pluralidade de sujeitos e de projetos (cf. Santos, 2005). Como insistentemente sublinha Cardoso (2005),

Importa reflectir sobre os interesses que são promovidos e sobre o que esses interesses estão fazendo à relação Estado-mercado-sociedade civil ... e fazêlo num quadro em que os resultados de qualquer iniciativa ou desenvolvimento são avaliados pela forma como os padrões de igualdade e de justiça social se manifestam em cada local (p. 113).

Assim, a genealogia da governação, inscrita nas transições, quer do regime de acumulação, quer do sistema político, situa os desenvolvimentos em discussão na gestação de formas políticas alternativas, em que capitalismo e democracia se interpelaram no bojo da instabilização do regime fordista de Estado de Bem-estar.

As dinâmicas de globalização inscrevem-se nestes processos, modelando-os e sendo alimentadas por eles. Considera-se, então, que as prioridades, orientações, demandas, problemas e soluções colocados e encontrados (constituindo uma agenda) para a educação, nos diversos espaços políticos relevantes (nacional, bloco regional, continental, 
subnacional), são construídos e impulsionados por pressões, exigências, protagonistas e processos globais. Estes consistem em feixes diferenciados, assimétricos, contraditórios e desequilibrados de "relações sociais de escala mundial" (Santos, 1997, p. 14), pelos quais "determinada condição ou entidade local estende a sua influência a todo o globo desenvolvendo a capacidade de designar como local outra condição social ou entidade rival" (Giddens, 1992, p. 50). Argumenta-se que as relações entre educação e globalização podem ser descritas e exploradas questionando os termos da agenda globalmente estruturada para a educação (que prioridades? que protagonistas? que estruturas? que processos?) (Antunes, 2004; Dale, 2001).

A discussão que a seguir se apresenta procura então elucidar alterações no papel do Estado, enquanto protagonista de políticas públicas que têm vindo a impulsionar mudanças em educação com impacto na concretização do bem-estar social e do direito da população portuguesa à educação. Este debate é enquadrado por investigações sobre as políticas públicas de criação e desenvolvimento do subsistema de escolas profissionais (de nível secundário) entre 1989-1998 e sobre a criação e desenvolvimento do dispositivo de reconhecimento, validação e certificação de adquiridos experienciais, no quadro da política de educação e formação de adultos, entre 1999-2011.

\subsection{Trajetórias de democratização, europeização e privatização da educação: Notas de pesquisas}

Em Portugal foram sendo constituídas nestas últimas décadas e são hoje observáveis múltiplas dinâmicas de privatização da educação, impulsionadas por medidas estatais, pela ação de setores e grupos mais ou menos organizados e autónomos (Associações EPIS, do Ensino Particular e Cooperativo, empresas) ou por estratégias das famílias (como ocorre com as 'explicações') (cf. Costa, Neto-Mendes, \& Ventura, 2008). No entanto, mesmo constituindo um tópico presente no debate político nas últimas décadas, com denúncias recorrentes e mesmo com investigações policiais e judiciais em curso, com ecos regulares na comunicação social ${ }^{4}$, esta problemática não tem originado um corpo de pesquisas científicas suficientemente vasto para permitir a constituição de conhecimento abrangente e consistente, pelo que persiste como uma espécie de face ignorada da realidade educacional no terreno. 
As políticas públicas, as dinâmicas e processos sociais associados às globalizações e à constituição da UE, a reestruturação da economia global em curso, também desde meados dos anos 70, a negociação da posição (semiperiférica?) da economia e da sociedade portuguesas, no quadro da UE (Santos, 2012), e as alterações estruturais da sociedade portuguesa (Costa, 2012) constituíram os principais motores e fatores envolvidos na construção do Estado de Bem-estar português, já em período dessíncrono, e até em contraciclo, face a mudanças em curso nas sociedades do centro e norte da Europa (Afonso, 1998). Nessa medida, em Portugal construímos o que alguns designam um semi-Estado-Providência (Santos, 1990) e vivemos, em consequência, a (sua) simultânea crise e consolidação da escola de massas, processo muito fortemente presente nos anos 90 (Stoer, 1994).

Para esclarecer a materialização de algumas destas mudanças socioeducativas são adiante convocados estudos recentes sobre o desenvolvimento de políticas educativas no país, neste período histórico em que se interseta(ra)m mudanças societais estruturais, com a instauração e consolidação da democracia (desde 1974) e a adesão à então Comunidade Económica Europeia (desde 1985/1986) e à moeda única (desde 1999/2001).

As políticas públicas são, assim, cruciais em Portugal, quer para sustentar a democratização da educação e os direitos sociais, quer para impulsionar reformas do Estado que, também desde os anos 90, bem se pode dizer foram a expressão da crise do semi-Estado de Bem-estar português. $\mathrm{Na}$ verdade, um dos primeiros afloramentos do debate sobre privatização da educação em Portugal ocorre desde os anos oitenta em torno do ensino superior, da educação de infância e da educação profissional (cf. Estêvão, 1998; Seixas, 2000; Vilarinho, 2000). Em qualquer destes casos, o domínio privado assumiu uma dimensão significativa, acolhendo largas percentagens dos inscritos. Naqueles setores, à época, o Estado não responde à demanda das populações através da estrutura pública e deliberadamente cria espaço para a expansão da oferta privada. Neste enquadramento, o Estado português optou, por ação e omissão, por promover a privatização e mercadorização da educação. Desde os anos 90, as políticas públicas dinamizaram uma evolução diferenciada em cada um dos setores, no que toca à provisão privada, ao papel assumido pelo Estado na governação 
(financiamento, provisão, regulação e propriedade) da educação (Dale, 1997), à configuração do direito e da democratização da educação.

A europeização da educação constitui, desde essa época, uma dinâmica de mudança sociopolítica estrutural do Estado e da sociedade portugueses, que articula a especificidade da simultânea crise e consolidação da escola de massas e do Estado de Bem-estar, de que o neoliberalismo educacional mitigado constitui uma expressão (Afonso, 1998; Antunes, 2004; Stoer, 1994).

\subsubsection{Europeização e gerencialismo: Um novo papel para o Estado em educação}

A adesão de Portugal à então Comunidade Económica Europeia, em 1986, abre caminho a um processo de profundas mudanças na sociedade e no Estado portugueses, que alguns investigadores, como Santos (1993), discutem em torno da forma do Estado como imaginação do Centro. Entre outros aspetos, aponta-se o modo como, através de "discursos e actos simbólicos", se regula "a dialéctica da distância e da proximidade, da diferença e da identidade entre Portugal e a Europa", mas também se "deslegitima qualquer especificidade do desenvolvimento nacional que não se enquadre nos atuais objetivos do Estado (por exemplo o setor empresarial do Estado) alegando que contrariam os padrões de desenvolvimento europeu, não sendo, por isso, politicamente defensáveis" (Santos, 1993, p. 51). Ao mesmo tempo, atuando num país imaginariamente do centro europeu, o Estado conseguiu com sucesso apreciável despolitizar áreas da política interna, invocando uma suposta inevitabilidade técnica de medidas exigidas em nome da integração europeia. Discutindo, no início dos anos 90, perplexidades e incertezas suscitadas pela "incógnita" do processo de integração europeia, Santos assumia certo pessimismo para concluir que "o discurso de coesão social europeia coexiste com a falência do Estadoprovidência e o avolumar das desigualdades sociais nos vários estadosmembros" (Santos, 1993, p. 53). Mais recentemente, no quadro de "um diagnóstico português" e argumentando que "se Portugal é o problema, a Europa, esta Europa, tão pouco é a solução" (Santos, 2012, p. 13), o autor defende que "a entrada na União Europeia transformou profundamente a sociedade portuguesa e, na esmagadora maioria dos casos, tratou-se de uma 
transformação positiva, para melhor" (Santos, 2012, p. 62). Outros chamam a atenção para a "economia política da integração europeia" como quadro de gestação de uma "assimetria estrutural europeia", particularmente alimentada pelo "segundo projeto de integração", em progressão desde 1987, com a criação do Mercado Único Europeu, o Tratado de Maastricht (1992) e o estabelecimento da zona monetária do Euro (1999/2001), enquanto prossegue a "financeirização das sociedades" (Reis, 2014, p. 11 e ss.). Simultaneamente, é possível observar e argumentar que a "integração europeia ... funcionou quase sempre não apenas como um motor para o alargamento dos direitos sociais dos portugueses mas também como um fator de legitimação da luta por esses direitos" (Hespanha, Ferreira, \& Pacheco, 2014, pp. 197), dados os elevados padrões de proteção e de bem-estar social em vigor na maior parte dos Estados-membros (p. 192). Neste quadro, os mesmos autores caraterizam as décadas de 1990 e 2000, em que aquela integração tem lugar, quanto à construção institucional do Estado de Bemestar em Portugal, como de tensão entre modelos de Estado de Bem-estar e, consequentemente, entre orientações mais promotoras da dependência do mercado ou visando o investimento social (Hespanha et al., 2014, pp. 197, 192). A trajetória das políticas sociais em Portugal oscilou, nesta época, entre uma perspetiva de forte intervenção do Estado no fornecimento de serviços e respostas e uma conceção de "desvinculação do Estado da promoção desses serviços ... com intervenção preferencial do Estado num papel subsidiário" (Hespanha et al., 2014, pp. 192-193).

No campo da educação, entre outras alterações, inicia-se o envolvimento do país em dinâmicas de europeização (Antunes, 2001) que assumem algumas especificidades, dadas as particulares condições das realidades educativas portuguesas, traduzidas, entre outras, pela simultânea crise e consolidação da escola de massas (e do Estado de Bem-estar), mas também do desenvolvimento num mesmo tempo das chamadas (e controversas) gerações de direitos: civis e políticos; económicos e sociais; e culturais (cf. Santos, 1997). A partir do final da década de oitenta do século $X X$, entra em força no debate público, político e académico a redefinição do papel do Estado na regulação, financiamento, propriedade e provisão da educação, a que corresponde a responsabilidade da criação de um sistema público universal de educação, atribuída pela Constituição da República 
Portuguesa de 1976. Esta questão ganhou acuidade naquele momento histórico face à expansão do ensino privado no nível superior e à criação, por iniciativa estatal, do sistema de escolas profissionais, de nível secundário e de âmbito nacional, com financiamento público, mas assumindo em regra um estatuto juridicamente privado (Antunes, 2001; Seixas, 2000). Aquela que foi designada a segunda década de transição (Afonso, 1998) instituía assim um novo papel para o Estado na educação em Portugal, que, em boa verdade, iniciava um percurso que haveria de consolidar-se nas décadas seguintes e envolve certas opções na organização dos serviços de bem-estar social conotadas com a reforma do Estado gerencial (Clarke \& Newman, 1997). A materialização desse novo papel ocorreria através de diversas políticas educativas que envolvem vários dos seguintes desenvolvimentos:

(i) a iniciativa do Estado, apelando à participação da sociedade civil na provisão de serviços e à mobilização social em torno da educação;

(ii) a contratualização do fornecimento de serviços educativos, definida como uma forma de partenariado socioeducativo com o Estado;

(iii) a delegação de competências, por esta via, num leque muito alargado de entidades que são envolvidas na prestação de serviços educativos, independentemente do seu estatuto jurídico, da sua natureza, história, vocação ou experiência;

(iv) a transferência sistemática de recursos públicos para o domínio privado, através da contratualização de serviços educativos;

(v) a expansão das respostas educativas, envolvendo públicos recémchegados, penalizados ou negligenciados pelo sistema de educação escolar regular.

É neste quadro que a governação da educação emerge em força como problemática e questionamento para compreender as políticas públicas e as mudanças relacionadas com a reforma e os papéis do Estado em educação ao lado de outras entidades vinculadas ao mercado ou ao chamado terceiro setor. Na divisão funcional de responsabilidades, essas entidades assumem a provisão, a propriedade da estrutura educativa, certos aspetos da regulação, enquanto as autoridades públicas (o Estado e a CE/UE) se retiram 
sobretudo das duas primeiras atividades, mantendo porém o financiamento e a regulação. A europeização da educação significou nesse período, entre outros aspetos, que o projeto de criação de um subsistema privado se tornou viável porque correspondeu e integrou as prioridades e opções perseguidas e veiculadas no quadro da Comunidade Europeia, naqueles domínios (Antunes, 2001).

Desde 1989 até hoje encontramos um leque de políticas públicas que sustenta este novo papel do Estado, impulsionado e enquadrado pelo financiamento proveniente da União Europeia, pela ampliação, que este permite, das respostas educativas e dos públicos abrangidos, pela retirada da provisão, evitando frequentemente a vinculação a políticas e estruturas públicas permanentes, que são substituídas por programas temporários e organismos provisórios, fomentados pelo mesmo financiamento. Sugere-se, por isso, que uma constelação visível e poderosa de tendências na educação escolar portuguesa dos últimos 25 anos associa a democratização, a europeização e a privatização da educação; esta constelação de tendências contraditória, mas persistentemente, configurou e configura a evasão do Estado ao seu compromisso com o direito à educação da população portuguesa, em particular aquela mais vulnerável e penalizada pelo sistema de educação formal regular. Este argumento é fundado na análise de algumas das políticas públicas de educação que, desde o final dos anos oitenta, se dirigem a estes segmentos menos poderosos e mais desprotegidos da população.

\subsubsection{A especificidade educativa portuguesa e a recontextualização de políticas comunitárias}

Portugal acorda com a (então designada) Comunidade Europeia o I Programa de Desenvolvimento Educativo para Portugal (PRODEP I, 19891994). Com base no diagnosticado défice de qualificações no país, o Estado português propõe e negoceia um programa de financiamento integrado nos Fundos Estruturais Europeus, que envolve a educação, ainda que apenas certas rubricas, como equipamentos, instalações, formação contínua de professores, ou segmentos integráveis ao abrigo da competência da Comunidade no domínio da formação profissional, como o ensino profissional ou superior. Mas este PRODEP é negociado muito antes de a Comunidade 
assumir uma competência formal de intervenção em educação, em 1992, no Tratado da União Europeia de Maastricht (cf. Nóvoa, 1998). Nesse sentido, o PRODEP I representou uma inovação na Comunidade Europeia, com implicações importantes para a europeização da educação em Portugal.

É assim que, em Portugal, encontramos em paralelo, mas não necessariamente articuladas, trajetórias de: (i) democratização da educação, traduzida pela expansão do acesso de mais amplos segmentos da população a níveis mais elevados de educação; (ii) europeização da educação, visível no envolvimento e entrosamento de recursos, prioridades e opções europeias nas políticas públicas nacionais de educação; (iii) privatização da educação, pela retirada do Estado da provisão e da propriedade, no caso do ensino profissional. Nesse sentido, pode argumentar-se que, no país, a europeização da educação fomenta a privatização da educação, já que os recursos financeiros provenientes dos Fundos Estruturais Europeus podem ser amplamente canalizados para instituições privadas, mas apenas cobrem rubricas muito restritas do sistema público, que tem de ser sustentado (quase) exclusivamente pelo orçamento de Estado. A estagnação do ensino secundário em Portugal, em termos de taxas de escolarização, a que assistimos durante cerca de 10 anos, entre 1994-2004, pode não ser alheia a este condicionamento decorrente do facto de o ensino profissional ser, na sua maior parte, sustentado por financiamentos europeus que não podiam, em paridade de condições, ser canalizados para o sistema público de educação.

Quais as implicações destes desenvolvimentos? Sustentou-se, por um lado, que esta nova modalidade de provisão da educação criou condições para o desenvolvimento de um quase-mercado em educação (cf. Antunes, 200; Le Grand \& Bartlett, 1993). Por outro lado, foram criadas escolas de profissionais docentes com vínculos precários, muitos acumulando com o vínculo a tempo inteiro no sistema público de educação, outros trabalhando em condições incertas, situação agravada frequentemente pelo caráter temporário dos programas de financiamento. A precarização de direitos sociais laborais foi, ao longo dos mais de 25 anos do subsistema de escolas profissionais, uma condição fortemente presente, ainda que verificando configurações e gravidade diversas nesse período. Também a precarização do direito fundamental da população portuguesa à educação foi uma condição presente neste subsistema, já que, mesmo se com materializações 
diferenciadas, o caráter privado da educação que aí era proporcionada exprimia-se também no facto de os estudantes pagarem anuidades de que em regra eram reembolsados, mas sobretudo de lhes serem cobrados, sem direito de reembolso, exames ou outras formas de avaliação adicionais, para além daquelas incluídas num percurso regular, bem como todo o tempo de frequência que, por qualquer motivo, excedesse a duração de três anos prevista para a conclusão dos cursos (cf. Antunes, 2004).

Para além do subsistema de escolas profissionais, a partir do final dos anos noventa teve lugar o desenvolvimento que ficou conhecido como o relançamento do sistema de educação de adultos, que, do ponto de vista da sua governação, verifica a quase totalidade dos desenvolvimentos atrás enunciados. Não está em questão o facto de que, do ponto de vista sociohistórico, o campo da educação de adultos apresenta especificidades que configuram uma responsabilidade do Estado assente no papel de suporte, coordenação e apoio de dinâmicas socioeducativas contextualizadas e autonomamente assumidas pela ação organizada e enraizada na sociedade. Argumenta-se antes que, entre 1999 e 2011, assistimos ao desenvolvimento de medidas assumidamente vinculadas ao Estado gerencial, como as que ressaltam da assunção do controlo estratégico centralizado na contratualização de serviços educativos, direcionados para alcançar objetivos definidos pelo Estado, com um enraizamento local e comunitário dificultado e um âmbito educativo limitado. Alguns protagonistas entendem mesmo que aquele relançamento do sistema de educação de adultos enfermou de um 'erro cruel' de promoção da provisão por entidades do setor privado lucrativo e do mercado da formação, que contaminaria a responsabilidade estrutural de qualificação da população com desvios derivados da sobreposição de interesses e motivações particulares, quer de operadores privados, quer de consumidores. Nesse sentido, o alargamento do círculo da governação (Santos, 2005) no campo da Educação e Formação de Adultos (EFA) revelaria alcance e preocupações de natureza sobretudo instrumental: as instituições envolvidas foram chamadas a executar e legitimar as políticas e os objetivos estatais, a compensar os défices de coesão e as fraturas abertas pelas opções económicas, a alimentar o laço social abalado pelas crises, inseguranças e riscos vitais e sociais criados pelas dinâmicas económicas (Antunes, 2013). 
Os estudos mostram, mesmo assim, haver sinais de que a apropriação das políticas pelos diversos protagonistas (instituições, profissionais, adultos) foi diversa, heterogénea e ambivalente, com a persistência de práticas e ação política divergente no terreno. Constata-se, no entanto, que o saldo final indubitavelmente revelado a partir de 2011 é a continuada ausência de uma política e de um sistema públicos, globais e permanentes de EFA como invariante estrutural (Lima, 2007) da democracia portuguesa.

Ainda no campo da educação profissional, agora voltada para públicos penalizados pelo sistema de ensino regular, sobretudo na educação básica, mas também secundária, a criação dos Cursos de Educação e Formação obedeceu aos mesmos parâmetros antes assinalados. Iniciou-se, de forma aberta, um processo com expressão variável em diferentes ciclos governativos: a desescolarização dos públicos jovens social e academicamente mais frágeis, com a desresponsabilização da escola pela sua educação, e a indiferenciação das instituições que de facto a assumem. O lançamento daqueles Cursos no início do século XXI configurou um passo decisivo neste processo, já que a educação dos públicos marcados pelo insucesso no final dos nove anos de ensino básico, tipicamente a partir dos 15 anos, passou a poder ocorrer nos mais diversos contextos institucionais, desde empresas de formação a escolas públicas e privadas ou centros de formação, autarquias, instituições do setor solidário, associações empresariais ou sindicatos (cf. Despacho conjunto n. ${ }^{\circ}$ 279/2002, de 12 de abril). A ampla diversidade de entidades consideradas competentes pelo Estado para prover a educação destes jovens em situação de insucesso ou abandono escolar exprime a tendência crescente de trivialização das respostas educativas de remediação. A difusão da função da formação (Barbier, 1995), traduzida pela alargada indiferenciação institucional, entrega a educação destes públicos já desfavorecidos, em demasiados casos, a provedores que não necessitam demonstrar uma natureza, história, organização, vocação ou experiência de caráter educativo, mas tão só de mobilizar recursos materiais e humanos, mesmo com vínculo laboral precário, compatíveis com o exercício daquela função.

Do mesmo modo, desde 2012, assistimos à canalização de jovens para instituições classificadas como 'externas' pelo Instituto de Emprego e Formação Profissional (IEFP), que tutela a modalidade dos Cursos de 
Aprendizagem (cf. IEFP, 2014). O leque de categorias das entidades que podem prover esses Cursos é alargado e são os jovens social e academicamente mais frágeis a ser entregues para serem educados em contextos, ambientes e instituições cujas capacidade e competência ninguém pública e regularmente avaliou, demonstrou ou legitimou. Tivemos notícias de vultuosos contratos associados a instituições e organizações empresariais, que configuraram a transferência organizada de recursos públicos para entidades privadas ${ }^{5}$, enquanto o sistema público de educação foi submetido a cortes orçamentais que depauperaram e ameaçaram minar a qualidade do serviço público. Por outro lado, a origem quer da retirada do financiamento às estruturas públicas, quer da sua canalização para operadores privados no mercado da formação, inscreveu-se tanto nas opções do governo português, como nas imposições dos credores internacionais. A União Europeia, por seu turno, continua a figurar nesta equação, por um lado como a fonte da maior parte do financiamento aplicado nestes Cursos de Aprendizagem, assim 'externalizados' face ao sistema público de educação e formação, e por outro lado como a inspiração daquelas opções de política educativa que dependeram, no entanto, em boa medida, do governo português.

Se a 'externalização' da educação destes jovens corresponde quase em partes iguais à ampliação do acesso, à privatização e à europeização da educação de nível secundário ${ }^{6}$, esta é a equação que traduz a alteração do papel do Estado na provisão do direito e do bem fundamental que é a educação, tal como surge materializada numa parte significativa das políticas públicas que, desde os anos oitenta, vêm reformando o Estado na educação em Portugal. Neste processo cabe perguntar: como fica o direito à educação destes jovens e adultos e a que educação têm eles direito através destas políticas públicas? Uma educação que os capacita para participar integralmente nas decisões e opções que condicionam as comunidades que constituem e a sociedade em que vivem? Que lhes proporciona os recursos e ferramentas para influenciar a vida e a organização das comunidades e contextos que definem as suas oportunidades e destinos sociais? Uma educação barata, minimalista e de segunda qualidade, centrada na missão de controlo social, que os 'externaliza' para os 'incluir' e os exclui no interior de um desvão institucional do sistema (Antunes \& Sá, 2014)?

Se o desenvolvimento dos sistemas educativos que consolidou o direito humano fundamental à educação ficou historicamente associado à 
especialização das funções institucionais, o século XXI tem vindo a alterar de múltiplas formas e decisivamente esse percurso: reforça-se a difusão da função social da formação, para uns, os desfavorecidos, ao mesmo tempo que se vincam as fronteiras do conhecimento escolar, para outros, na senda da excelência; prossegue a fabricação dos contornos do espaço educacional e a divisão funcional das responsabilidades de modos que segmentam e estratificam obscura e heterogeneamente o universo educativo. Aí se desenham fluxos e trajetórias locais e globais dos sujeitos, conexões e distinções entre os domínios público e privado que temos dificuldade em elucidar e compreender.

\section{Considerações finais: Sobre a relação entre a intervenção do Estado e do domínio privado em educação - Interlocuções em torno da democratização e do direito à educação no Brasil e Portugal}

Este diálogo entre pesquisas procurou construir pontes entre agendas de investigação, articulações entre ferramentas analíticas e concetuais, conexões de percursos teórico-metodológicos e possibilidades de aprofundamento de questionamento e de conhecimento sobre realidades distintas, que podem ser melhor observadas e compreendidas se aproximadas a partir de olhares cruzados entre investigações.

O programa delineado para o debate neste texto partiu do reconhecimento de que as pesquisas evocadas, sendo construídas a partir de referenciais teórico-metodológicos diferenciados, pareciam colocar questões convergentes e recortar fenómenos com aproximações significativas, ao mesmo tempo que as realidades empíricas, apresentando incontornáveis diferenças e especificidades, também apontavam percursos entre os quais as pontes e diálogos se constituíam convincentemente. Por outro lado, as problemáticas e as ferramentas concetuais que constroem, observam e elucidam os fenómenos são específicas, porque se vinculam a comunidades científicas e contextos social e historicamente situados; entretanto, elas partilham uma abordagem da realidade que privilegia a análise de relações, processos e dinâmicas sociais (p. ex., o Estado como relação social conflitual e a sociedade civil como terreno em que se confrontam sujeitos e projetos societais distintos), suscitando preocupações e interpelações mutuamente 
enriquecedoras. Neste quadro, a par de estudos e autores comuns, a interlocução é ainda favorecida pelo uso das mesmas ou similares categorias de observação dos fenómenos, como provisão, financiamento e regulação da educação, convocadas nas pesquisas de ambos os países; acresce ainda a fertilidade do diálogo entre autores e abordagens para enriquecer o conhecimento sobre tema tão complexo, revelando fenómenos e cambiantes diversos em realidades também elas polifacetadas.

Assim, o mote do debate foi a interrogação acerca de como as pesquisas que desenvolvemos nos elucidam sobre os modos e os sentidos em que o Estado assume novos papéis, impulsionados e enquadrados por políticas públicas de educação; não pretendemos construir uma argumentação geral, mas discutir a partir de trajetórias concretas de investigações sobre o tema. Nesse sentido, perguntamos: afinal, como se relaciona o Estado com o setor privado em educação? Observamos que em alguns casos financia, em outros o financiamento é privado; em alguns casos o poder público permanece no controlo, e em outros o privado assume a direção e o controlo das políticas. Enfim, são muitas as formas de relação entre o público e o privado no que se refere à oferta e ao conteúdo da educação básica e secundária.

Estes estudos situam-se no recente período de cerca de três décadas, em que vivemos no Brasil e em Portugal a transição para a democracia e a construção de políticas públicas de bem-estar social, quando estava já posta em causa a forma política de Estado que mais longe levou essa tentativa de compatibilização incessantemente precária e disputada entre capitalismo e democracia (Santos, 1990); tratava-se ainda de entender que implicações decorrem desses processos de mudanças sociais e educacionais em termos de democratização e concretização do direito à educação.

Através de referenciais teóricos e ferramentas analíticas e concetuais específicas, mesmo se dialogantes, percebemos que, no Brasil e em Portugal, na sequência de percursos socio-históricos distintos de construção da escola básica/fundamental (9 anos de escolaridade) universal, e de recente obrigatoriedade do ensino secundário/médio (12 anos de escolaridade), as taxas de cobertura da estrutura privada de educação apresentam um valor significativo e não demasiado distante: para o Brasil, 15,73\% no ensino fundamental e 13,25\% no ensino médio; em Portugal, 19,3\% dos estudantes 
no ensino não-superior. Merecem, no entanto, ser entendidos os ritmos de expansão, as taxas de reprovação, de escolarização e de atraso, bem como a distribuição e a caraterização dos públicos atendidos por cada uma das redes, pública e privada, para que aquela aproximação ganhe sentido, para além desta constatação, em si mesma com algum significado.

Por outro lado, a ampliação do acesso ao direito à educação para novos públicos, através de novas respostas educativas, ocorre frequentemente nos dois países, no quadro de políticas públicas de teor gerencial, em que o Estado se retira da provisão e da propriedade da estrutura educativa, mantendo o financiamento e a regulação. Por esta via, múltiplos processos são desencadeados, com significados distintos: (i) a criação de condições para o estabelecimento de quase-mercados educativos, com entidades da sociedade civil concorrendo por contratos de provisão de serviços educativos; (ii) a instauração de relações privadas dos cidadãos com a educação, no âmbito da resposta pública; (iii) a constituição de corpos de profissionais (muitas vezes precários), cujas condições laborais, ou mesmo caraterísticas, se distanciam do padrão do sistema público, apesar de operarem no quadro de uma resposta pública; (iv) a expansão do poder do Estado, por dentro da sociedade civil, delegando competências e poderes, mantendo frequentemente o controlo estratégico; (v) mas também a canalização de segmentos dos públicos, tendencialmente mais desfavorecidos e frágeis social e academicamente, para fora da escola e/ou para entidades externas ao sistema público de educação e formação.

Como antes se observou, aquando da apresentação dos estudos, no Brasil como em Portugal, salvaguardadas significativas especificidades (como a articulação de processos de europeização, democratização e privatização da educação em Portugal), a contratualização da provisão de educação é mobilizada como estratégia para ampliar a resposta educativa, sem ampliar a estrutura pública e sem a constituição de um corpo de profissionais especializados que estiveram na base da construção dos sistemas públicos de educação no âmbito dos Estados de Bem-estar mais sólidos e desenvolvidos. Nesse sentido, a concretização precarizada do direito à educação para públicos tantas vezes socialmente vulneráveis atribui às políticas públicas estudadas um sentido de seletividade e mesmo de discriminação social que fragiliza a democratização e a cidadania prometidas pela ampliação do acesso à educação. 
O referencial teórico mobilizado situa o atual momento de crise do capitalismo e permite compreender que as democracias, mais consolidadas ou mais recentes, como no Brasil e em Portugal, têm reconstruído o Estado em moldes tais que à crescente centralidade da educação nas políticas públicas corresponde, entre outros fenómenos, uma ampliação das respostas e das populações abrangidas, acompanhada da multiplicação das modalidades de privatização e de mercadorização da educação. Esta conjugação, em boa medida inesperada e observada em ambos os países, não pode deixar de suscitar interrogações sobre os sentidos da democratização e da ampliação do direito à educação neste contexto.

O processo de mercantilização ocorre também com o setor privado a definir o conteúdo da educação. Neste caso, observamos o poder público a assumir a lógica do privado na administração pública, em parte através da gestão gerencial e também quando abdica de decidir o conteúdo da educação, transferindo a direção para instituições privadas. Este diagnóstico parte do argumento neoliberal (Buchanan et al., 1984), que aponta as instituições democráticas contemporâneas como irresponsáveis e promove a solução de adotar medidas restritivas constitucionais para conter os governos, colocando-se os instrumentos de controlo fora das instituições representativas; parte-se do princípio de que os controlos políticos são inferiores ao de mercado e de que o privado tem o padrão de qualidade a ser implementado nas instituições públicas, para que sejam mais eficientes e produtivas.

As escolas são instituições públicas permeáveis à correlação de forças - se democráticas - onde não se tem previamente o controlo do produto. São instituições de propriedade pública, mas se o processo decisório está ausente, já que tudo é previamente definido e monitorizado por uma instituição privada e os professores apenas executam tarefas, entendemos que também ali ocorre um processo de privatização da educação.

Com a retirada das decisões do domínio público, a instituição pública não é "vendida", no sentido da perda da propriedade, mas esvaziada como espaço público decisório, minimizando esse seu papel, mesmo em democracia. Questionamos: quem define a educação, quem dirige e com base em que parâmetros? Entendemos que existem projetos societais em disputa. Assim, mesmo quando a oferta permanece pública, há implicações 
para um projeto societal democrático se a direção das políticas é realizada por instituições que tenham como parâmetro os pressupostos de mercado, principalmente em países com processos tão recentes de construção democrática.

\section{Financiamento}

As pesquisas que sustentam este artigo foram financiadas por fundos nacionais do CNPq - Conselho Nacional de Desenvolvimento Científico e Tecnológico do Brasil e da FCT - Fundação para a Ciência e a Tecnologia (Projeto PEst-OE/CED/UI1661/2014) de Portugal.

\section{Notas}

1 Fonte: IBGE (Instituto Brasileiro de Geografia e Estatística), dados de 2014.

2 Sobre o financiamento e controlo social das instituições do terceiro setor no Brasil, ver Peroni (2006).

3 O Plano de Desenvolvimento da Educação foi lançado em 2007, pelo Ministério da Educação, com o objetivo de promover a melhoria da qualidade da educação pública brasileira. Este Plano contém um Plano de Metas, em que os estados e municípios elaboram os seus Planos de Ações Articuladas (PAR) com base no diagnóstico das suas necessidades.

4 Ver, por exemplo: http://www.publico.pt/sociedade/noticia/judiciaria-faz-buscas-emcolegios-do-grupo-gps-1620493.

5 Cf. http://www.jornaldasoficinas.com/pt/mercado/item/1664-iefp-e-atec-reforcamparceria-para-o-sistema-dual ou https://www.atec.pt/en/academia-formacaoatec/quem-somos.html (consultado a 6 de outubro de 2014). Segundo a última página eletrónica referida, a ATEC - Associação de Formação para a Indústria tem como promotores a Volkswagen Autoeuropa, a Siemens, a Bosch e a C.C.I.L.A. (ou AHK - Câmara de Comércio e Indústria Luso-Alemã).

6 No caso dos Cursos de Educação e Formação ou dos mais recentes Cursos Vocacionais, estava envolvido também o nível básico de educação ( 9 anos de escolaridade) e podia, na segunda modalidade, abranger crianças a partir dos 13 anos.

\section{Referências}

Adrião, T. (2014). Escolas charters nos EUA: Contradições de uma tendência proposta para o Brasil e suas implicações para a oferta da educação pública. Educação e Filosofia, 28, 263-282. 
Adrião, T., \& Garcia, T. (2014). Subsídio público ao setor privado: Reflexões sobre a gestão da escola pública no Brasil. Revista Políticas Educativas, 7(2) , 110-122.

Adrião, T., \& Peroni, V. (2010). Análise das consequências de parcerias firmadas entre municípios brasileiros e a Fundação Ayrton Senna para a oferta educacional (Relatório de pesquisa não publicado).

Adrião, T., Garcia, T., Borghi, R., \& Arelaro, L. (2009).Uma modalidade peculiar de privatização da educação pública: A aquisição de 'sistemas de ensino' por municípios paulistas. Educação \& Sociedade, 30(108), 799-818.

Afonso, A. J. (1998). Políticas educativas e avaliação educacional. Para uma análise sociológica da reforma educativa em Portugal (1985-1995). Braga: Universidade do Minho.

Antunes, F. (2001). Os locais das Escolas Profissionais: Novos papéis para o Estado e a europeização das políticas educativas. In S. R. Stoer, L. Cortesão, \& J. A. Correia (Orgs.), Transnacionalização da educação. Da crise da educação à 'educação' da crise (pp. 163-208). Porto: Afrontamento.

Antunes, F. (2004). Políticas educativas nacionais e globalização. Novas instituições e processos educativos. O subsistema de Escolas Profissionais em Portugal (1987-1998). Braga: Universidade do Minho.

Antunes, F. (2013). Reforma do Estado e políticas públicas: A governação em ação. Notas de um estudo no campo da educação e formação de adultos em Portugal. In V. Peroni (Org.), Redefinições das fronteiras entre o público e o privado: Implicações para a democratização da educação (pp. 82-119). Brasília: Liber Livro Editora.

Antunes, F., \& Sá, V. (2014). Cursos de educação e formação, política e pedagogia da educação universal: Histórias em torno do saber e do poder na escola. In M. L. P. Almeida, L. W. Boneti, \& T. Pacievitch (Orgs.), O social e as políticas educacionais na contemporaneidade: Das desigualdades à violência no espaço educacional (pp. 207-245). Campinas: Mercado de Letras.

Antunes, R. (1999). Os sentidos do trabalho: Ensaios sobre a afirmação e a negação do trabalho. São Paulo: Boitempo Editorial.

Ball, S. (2012). Global education INC. New policy networks and the neo-liberal imaginary. Londres: Routledge.

Ball, S., \& Junemann, C. (2012). Networks, new governance and education. Bristol: Policy Press.

Ball, S., \& Olmedo. A. (2013). A "nova" filantropia, o capitalismo social e as redes de políticas globais em educação. In V. Peroni (Org.), Redefinições das fronteiras entre o público e o privado: Implicações para a democratização da educação (pp. 33-47). Brasília: Liber Livro.

Barbier, J.-M. (1995). Tendances d'évolution de la formation et place du partenariat. In D. Zay \& A. Gonnin-Bolo (Orgs.), Établissements et partenariats. Stratégies pour des projects communs (pp. 43-54). Paris: Institut National de Recherche Pédagogique.

Bernardi, L., Uczak, L., \& Rossi A. (2015). Do Movimento 'Todos pela Educação' ao Plano de Ações Articuladas e Guia de Tecnologias: Empresários interlocutores e clientes do Estado. Trabalho apresentado na ANPAE/Sul, UDESC, Florianópolis, Brasil. 
Bittencourt, J., \& Oliveira, M. F. (2013). A influência das consultorias internacionais nas decisões das políticas educacionais no Brasil. In V. Peroni (Org.), Redefinições das fronteiras entre o público e o privado: Implicações para a democratização da educação (pp. 175-197). Brasília: Liber Livro.

Borowsky, F. (2013). A relação entre a educação pública e a privada na Educação Especial brasileira. In V. Peroni (Org.), Redefinições das fronteiras entre o público e o privado: Implicações para a democratização da educação (pp. 308326). Brasília: Liber Livro.

Brasil. Ministério da Educação/Secretaria de Educação Básica (2011a). Guia de tecnologias educacionais 2011/12. Brasília: Ministério da Educação.

Buchanan, J. M., MacCormick, R., Tollison, R. D., \& Pardo, J. C. (1984). El análisis económico de lo político: Lecturas sobre la teoría de la elección pública. Madrid: Instituto de Estudios Económicos.

Caetano, M. R., \& Peroni, V. (2015). Ensino Médio no Brasil e a proposta educacional do Instituto Unibanco: Considerações sobre a mercantilização da educação pública. In V. Peroni (Org.), Diálogos sobre as redefinições no papel do Estado e nas fronteiras entre o público e o privado na educação (pp. 89-107). São Leopoldo: Oikos.

Cardoso, C. (2005). O público no privado e o privado no público em Portugal e na Inglaterra. In T. Adrião \& V. Peroni (Eds.), O público e o privado na educação. Interfaces entre Estado e sociedade (pp. 81-117). São Paulo: Xamã.

Clarke, J., \& Newman, J. (1997). The managerial State. Londres: Sage.

Comerlato, D., \& Moraes, J. (2013). AlfaSol e Programa Brasil Alfabetizado: A parceria público-privada nas políticas de educação de jovens e adultos. In V. Peroni (Org.), Redefinições das fronteiras entre o público e o privado: Implicações para a democratização da educação (pp. 327-346). Brasília: Liber Livro.

Costa, A. (2012). Desigualdades sociais contemporâneas. Lisboa: Mundos Sociais.

Costa, J., Neto-Mendes, A., \& Ventura, A. (2008). Xplika: Investigação sobre o mercado das explicações. Aveiro: Universidade de Aveiro.

Dale, R. (1997). The State and the governance of education: An analysis of the restructuring of the State-education relationship. In A. H. Halsey, H. Lauder, P. Brown, \& A. Wells (Eds.), Education - Culture, economy and society (pp. 273282). Nova lorque: Oxford University Press.

Dale, R. (2001). Globalização e educação: Demonstrando a existência de uma «cultura educacional mundial comum» ou localizando uma «agenda globalmente estruturada para a educação»? Educação, Sociedade \& Culturas, 16, 133-169.

Estêvão, C. V. (1998). Redescobrir a escola privada portuguesa como organização: $\mathrm{Na}$ fronteira da sua complexidade organizacional. Braga: Instituto de Educação e Psicologia/CIEd.

Giddens, A. (1992). As consequências da modernidade. Oeiras: Celta.

Giddens, A. (2001). A Terceira Via: Reflexões sobre o impasse político atual e o futuro da social-democracia. Rio de Janeiro: Record.

Hespanha, P., Ferreira, S., \& Pacheco, V. (2014). O Estado social, crise e reformas. In J. Reis (Coord.), A economia política do retrocesso. Crise, causas e objectivos (pp. 189-281). Coimbra: Almedina. 
IEFP/Instituto de Emprego e Formação Profissional (2014). Relatório mensal. Execução física e financeira. Valores acumulados a 30 de setembro de 2014. Disponível em: https://www.iefp.pt/documents/10181/747525/Relatorio+de+Execu\% C3\%A7\%C3\%A3o+Financeira+setembro+2014.pdf/ 5649afcd-bec5-4397-8bfc7f062b98d71d (acesso 27 de novembro de 2014).

Jessop, B. (1995). The regulation approach, governance and post-Fordism: Alternative perspectives on economic and political change? International Journal of Human Resource Management, 24(3), 307-333.

Junemann, C., \& Ball, S. (2013). ARK and the revolution of state education in England. Education Inquiry, 4(3), 423-441. Disponivel em: http://dx.doi.org/10.3402/ edui.v4i3.22611

Laval, C. (2004). A escola não é uma empresa. O neo-liberalismo em ataque ao ensino público. Londrina: Ed. Planta.

Le Grand, J., \& Bartlett, W. (Orgs). (1993). Quasi markets and social policy. Londres: The Macmillan Press.

Lima, L. C. (2007). Educação ao longo da vida. Entre a mão direita e a mão esquerda de Miró. São Paulo: Cortez.

Marginson, S. (1997). Markets in education. St. Leonard's, NSW: Allen \& Unwin.

Newman, J., \& Clarke, J. (2012). Gerencialismo. Educação \& Realidade, 37(2), 353381. Disponivel em: http://dx.doi.org/10.1590/S2175-62362012000200003

Nóvoa, A. (1998). Histoire \& comparaison: Essais sur l'éducation. Lisboa: Educa.

Peroni, V. (2003). Política educacional e papel do Estado no Brasil dos anos 90. São Paulo: Xamã.

Peroni, V. (2006). Conexões entre o público e o privado no financiamento e gestão da escola pública. Eccos - Revista Científica, 8(1), 111-132.

Peroni, V. (2011). Público/privado na Educação Especial em tempos de redefinições no papel do Estado. In M. Kassar (Org.), Diálogos com a diversidade: Sentidos da inclusão (pp. 39-60). Campinas: Mercado de Letras.

Peroni, V. (2013). As relações entre o público e o privado nas políticas educacionais no contexto da terceira via. Currículo sem Fronteiras, 13(2), 234-255.

Peroni, V. (2015). Implicações da relação público-privada para a democratização da educação no Brasil. In V. Peroni (Org.), Diálogos sobre as redefinições no papel do Estado e nas fronteiras entre o público e o privado na educação (pp. 15-34). São Leopoldo: Oikos.

Peroni, V. (2016). Implicações da relação público-privada para a democratização da educação no Brasil (Tese de promoção a Professor Titular da Carreira do Magistério Superior). Universidade Federal do Rio Grande do Sul, Porto Alegre, Brasil. Disponível em: https://plone.ufrgs.br/gprppe/teses

Pires, D. O. (2015). A construção histórica da relação público-privada na promoção do direito à educação no Brasil (Tese de Doutorado). Universidade Federal do Rio Grande do Sul, Porto Alegre, Brasil.

Reis, J. (2014). Apresentação. In J. Reis (Coord.), A economia política do retrocesso. Crise, causas e objectivos (pp. 9-19). Coimbra: Almedina. 
Rhodes, R. A. W. (1996). The new governance: Governing without government. Political Studies, 44(4), 652-667.

Rikowski, G. (2014). Crises in education, crises of education. Paper prepared for the Philosophy of Education Seminars at the University of London, Institute of Education, 2014-15.

Robertson, S., \& Verger, A. (2012). A origem das parcerias público-privada na governança global da educação. Educação \& Sociedade, 33(121), 1133-1156.

Robertson, S., Mundy, K., Verger, A., \& Menashy, F. (2012). Public private partnerships in education: New actors and modes of governance in a globalizing world. London: Elgar Publishing Limited.

Rodrigues, R., \& Santos, M. (2013). O programa nacional de acesso ao ensino técnico e emprego - Pronatec: Um olhar a partir das relações entre o público e o privado. In V. Peroni (Org.), Redefinições das fronteiras entre o público e o privado: Implicações para a democratização da educação (pp. 290-307). Brasília: Liber Livro.

Santos, B. S. (1990). O Estado e a sociedade em Portugal (1974-1988). Porto: Afrontamento.

Santos, B. S. (1993). Portugal: Um retrato singular. Porto: Afrontamento.

Santos, B. S. (1997). Por uma concepção multicultural de direitos humanos. Revista Crítica de Ciências Sociais, 48, 11-32.

Santos, B. S. (2001). Os processos de globalização. In B. S. Santos (Org.), Globalização. Fatalidade ou utopia? (pp. 31-106). Porto: Afrontamento.

Santos, B. S. (2005). A crítica da governação neoliberal: O Fórum Social Mundial como política e legalidade cosmopolita subalterna. Revista Crítica de Ciências Sociais, 72, 7-44.

Santos, B. S. (2012). Portugal. Ensaio contra a autoflagelação. Coimbra: Almedina.

Seixas, A. M. (2000). O ensino superior privado em Portugal: Políticas e discursos. Revista Portuguesa de Educação, 13(2), 53-79.

Stoer, S. (1994). O Estado e as políticas educativas: Uma proposta de mandato renovado para a escola democrática. Revista Crítica de Ciências Sociais, 41, 333.

Susin, M. O. (2009). A qualidade na educação infantil comunitária em Porto Alegre: Estudo de caso em quatro creches conveniadas (Tese de Doutorado). Universidade Federal do Rio Grande do Sul, Porto Alegre, Brasil.

Vieira, E. (1998). O Estado e a sociedade civil perante o ECA e a LOAS. Serviço Social \& Sociedade, 56, 9-23.

Vilarinho, M. E. (2000). Políticas de educação pré-escolar em Portugal (1977-1997). Lisboa: Instituto de Inovação Educacional.

Wood, E. M. (2014). O império do capital. São Paulo: Boitempo. 


\section{Legislação consultada}

Brasil. Ministério da Educação (2011b). Lei no 12.513, de 26 de outubro. Institui o Programa Nacional de Acesso ao Ensino Técnico e Emprego (PRONATEC). Brasília, Distrito Federal.

Brasil. Ministério da Educação/Fundo Nacional de Desenvolvimento da Educação (2012). Resolução CD/FNDE $n^{\circ} 44$, de 05 de setembro de 2012. Disponível em: http://portal.mec.gov.br (consultado em 27 de julho de 2015). 


\title{
STATE REFORMS AND PUBLIC POLICIES: PATHWAYS OF DEMOCRATIZATION AND PRIVATIZATION IN EDUCATION. BRAZIL AND PORTUGAL, A DIALOGUE BETWEEN RESEARCH STUDIES
}

\begin{abstract}
On the basis of concrete empirical research trajectories, the article addresses how the State relates to the private sector regarding education, and what the implications to democratization and the right to education in Brazil and Portugal are. The ways and the meanings in which the State takes on new roles are analysed, keeping public funding in some cases, whereas in others the funding is private; in some situations public power remains in control and in others private actors take the direction and control of the policies. In this sense, the growing centrality of education in public policies seems to correspond, among other phenomena, to an expansion of educational responses and of the populations concerned, accompanied by the multiplication of the modalities of privatization and commodification of education. It is concluded that the market logic has actively participated in the direction and execution of educational policies, with serious consequences for the process of democratization.
\end{abstract}

Key-words

Redefinition of the role of the State; educational policies; marketization of education; the right to education; managerialism

\section{RÉFORMES DE L'ÉTAT ET POLITIQUES PUBLIQUES: TRAJECTOIRES DE DÉMOCRATISATION ET DE PRIVATISATION DE L'ÉDUCATION. BRÉSIL ET PORTUGAL, UN DIALOGUE DE RECHERCHES}

\section{Résumée}

En s'appuyant sur des recherches empiriques, l'article discute des relations entre l'Etat et le secteur privé dans l'éducation et quelques de ses implications 
pour la démocratisation et le droit à l'éducation au Brésil et au Portugal. On analyse des formes et des sens dont l'Etat assume de nouveaux rôles, restant le financement public dans certains cas, tandis qu'en d'autres le financement est privé; dans quelques situations, le pouvoir public retient le contrôle et dans d'autres le secteur privé prend la direction et le contrôle des politiques. En ce sens, à la centralité croissante de l'éducation dans les politiques publiques semble correspondre, entre autres phénomènes, un élargissement soit des réponses soit de la population concerné, accompagnée par la multiplication des formes de privatisation et de la marchandisation de l'éducation. On conclut que la logique du marché a contribué activement à la direction et à l'exécution des politiques éducatives, avec de graves conséquences pour le processus de démocratisation.

Mots-clés

Redéfinition du rôle de l'Etat ; politiques éducatives ; managérialisme ; marchandisation de l'éducation ; droit à l'éducation

Recebido em fevereiro/2016 Aceite para publicação em novembro/2016

i Centro de Investigação em Educação, Instituto de Educação, Universidade do Minho, Portugal. ii Programa de Pós-Graduação em Educação, Faculdade de Educação, Universidade Federal do Rio Grande do Sul, Brasil.

Toda a correspondência relativa a este artigo deve ser enviada para: Maria de Fátima Magalhães Antunes Gonçalves Teixeira, Centro de Investigação em Educação, Instituto de Educação, Universidade do Minho, Campus de Gualtar, 4710-057 Braga, Portugal. E-mail: fantunes@ie.uminho.pt 